\title{
Particle Dispersion in the Western Mediterranean Basin
}

\author{
Dalila Elhmaidi ${ }^{*}$, , Halima Nefzi ${ }^{1}$, Xavier Carton $^{2}$ and Taieb Lili ${ }^{1}$ \\ ${ }^{1}$ Laboratoire de Mécanique des Fluides, Faculté des Sciences de Tunis, Tunisia \\ ${ }^{2}$ Laboratoire de Physique des Océans - Université de Bretagne Occidentale, Brest, France
}

\begin{abstract}
We used the Regional Ocean Modelling System (ROMS) to study the effect of mesoscale coherent structures on the dispersive properties in the western Mediterranean Sea where the mesoscale activity is highly inhomogeneous and anisotropic. We analyzed the transport properties of an ensemble of Lagrangian particles homogenously seeded at the surface and at $500 \mathrm{~m}$ depth. We showed the existence of a superdiffusive dispersion regime, which occurs especially in the upper ocean. The behavior of the particle dispersion is the superposition of two distinct regimes of two-dimensional turbulence, associated with the hyperbolic and the elliptic domains.
\end{abstract}

Keywords: Particle dispersion, Superdiffusive dispersion regime, western Mediterranean basin.

\section{INTRODUCTION}

The western Mediterranean Sea is well known for its rich mesoscale activities due to the interaction between the denser Mediterranean water and the light Atlantic one which penetrates from the Gibraltar Strait. It constitutes a major economic component for neighboring countries. So, it has been studied both via measurement programs and numerical models [1-6]. At the surface, the Atlantic water inflow, from west to east along the African coast and forms the Algerian Current which becomes unstable with a creation of meanders and vortices named "Algerian eddies". The Algerian Current flows through the Strait of Sardinia and splits into two branches at the Strait of Sicily: one follows a cyclonic path around the western Mediterranean basin and the other goes to the eastern Mediterranean Sea. At intermediate depth, the circulation is dominated by the warm and salty water formed in the eastern Mediterranean basin at depths of $200-500 \mathrm{~m}$. This water enters the Tyrrhenian Sea where it recirculates cyclonically and leaves it to enter the Algerian basin through the Strait of Sardinia from east to west $[1,7]$.

Algerian Eddies have a strong impact on the surface and intermediate circulations, and on the water mass distribution. They transport heat, salt and nutrients, and then contribute to the mixing process. Theoretical and numerical simulations have shown the importance of coherent vortices in the local dispersion and their role in the evolution of tracer concentration $[8,9]$.

In the present work, we have used a primitive equation model to represent the large- and meso-scale circulations of the western Mediterranean Sea where the meso-scale activity is highly inhomogeneous and anisotropic. We calculated the effect of the oceanic currents on particle dispersion at intermediate times.

*Address correspondence to this author at the Laboratoire de Mécanique des Fluides, Faculté des Sciences de Tunis, Tunisia; Tel: 21671872 600; Fax: 21671885073 ;

E-mails: dalila.elhmaidi@fst.rnu.tn, dalilaelhmaidi@yahoo.fr

\section{MODEL USED}

The Regional Ocean Modeling System (ROMS) is a high-resolution primitive equation model to simulate both coastal and oceanic regions. It is based on the Boussinesq approximation and on the hydrostatic balance. ROMS is a split-explicit, free surface oceanic model discretised in coastline and terrain-following curvilinear coordinates. Short time-steps are used to solve the barotropic momentum equations and longer ones to advance the baroclinic momentum equations. A third-order, upstream-biased advection scheme implemented in ROMS allows the generation of steep gradients, enhancing the effective resolution of the solution for a given grid size $[10,11]$. The explicit lateral viscosity is zero everywhere in the model domain except in the sponge layers near the boundaries where the viscosity increases smoothly toward the lateral open boundaries.

The computational domain extends from $33^{\circ}$ to $44.5^{\circ} \mathrm{N}$ and from $7^{\circ} \mathrm{W}$ to $15^{\circ} \mathrm{E}$. The model grid, forcing, initial and boundary conditions are built using the ROMSTOOLS package $[11,12]$. The bottom topography is derived from a 2 ' resolution database ETOPO2 [13]. A slope parameter $r$ $=2.5$ is used to prevent errors in the computation of pressure gradient [14]. The ROMS configuration is $1 / 5^{\circ}$ horizontal resolution and 20 vertical levels with stretched s-coordinates, using surface and bottom stretching parameters $\left(\theta_{s}=6\right.$, $\left.\theta_{b}=0\right)$ [15]. Mean monthly temperature and salinity data are obtained from World Ocean Atlas (WOA2005) database (monthly climatology at $1^{\circ} \times 1^{\circ}$ resolution) [16]. Fig. (1) represents the grid model and its bathymetry. At the two open boundaries facing the ocean (west and east), an active, implicit, upstream biased radiation condition connects the model solution to the surrounding ocean [17]. The model is forced with winds, heat and salinity fluxes from the Comprehensive Ocean-Atmosphere Data Set (COADS05), which is a monthly climatology giving data with spatial resolution of $0.5^{\circ}[18]$. The width of the nudging border is $150 \mathrm{~km}$ and the maximum viscosity value for the sponge layer is set to $1000 \mathrm{~m}^{2} \mathrm{~s}^{-1}$. 


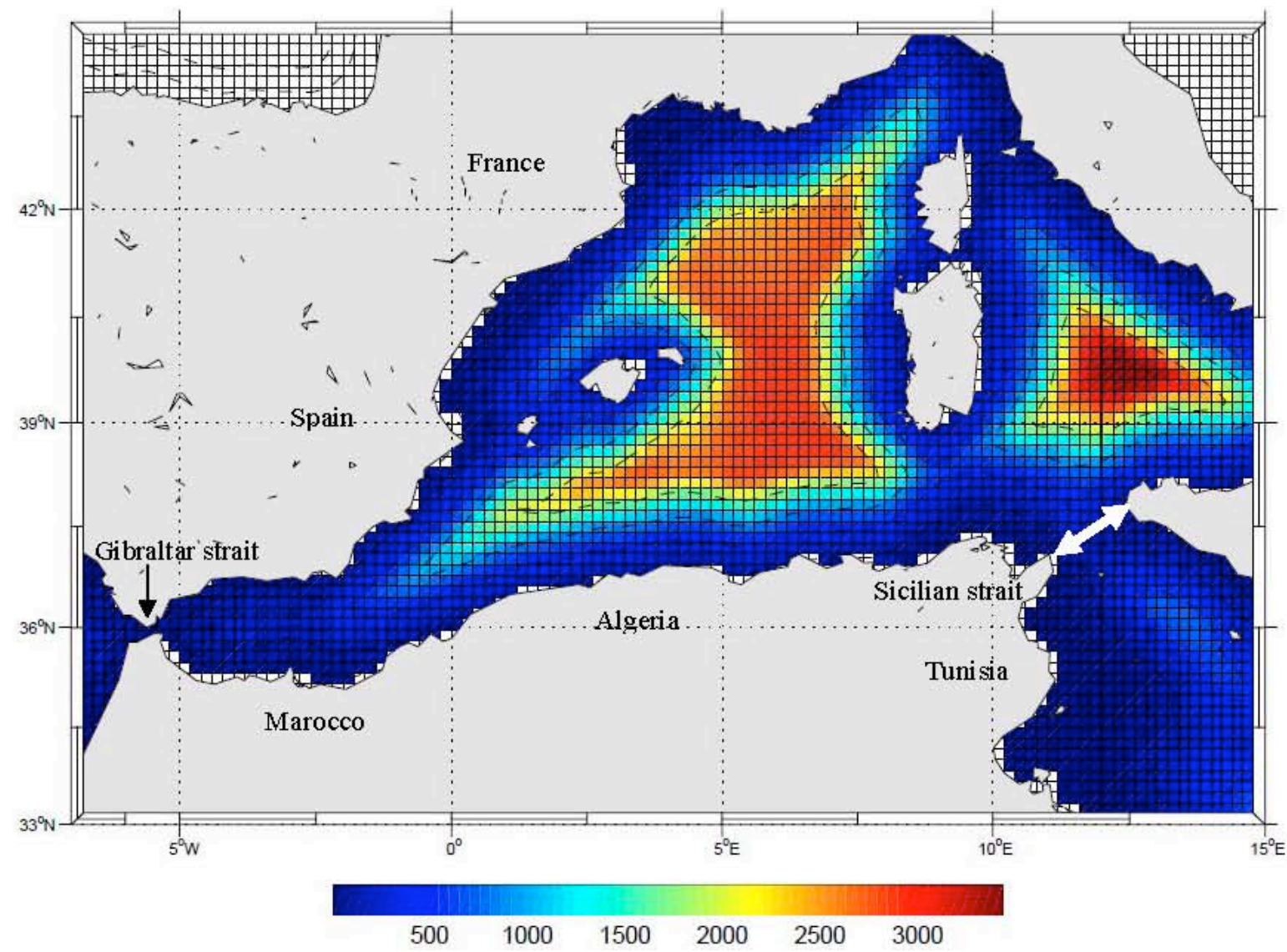

Fig. (1). The model domain and its bathymetry (m). The countries bordering the western Mediterranean sea, the Gibraltar and the Sicilian straits are reported for geographical information.

We run the model 13 years simulations to test its ability to reproduce the main circulation and capture the most eddies in the western Mediterranean sea. The model outputs are stored every month of simulation. We reported in
Figs. (2a) and (2b) respectively the temporal evolutions of the surface averaged and volume averaged kinetic energies. They revealed that the statistical equilibrium of the model is reached after a spin up of two years.
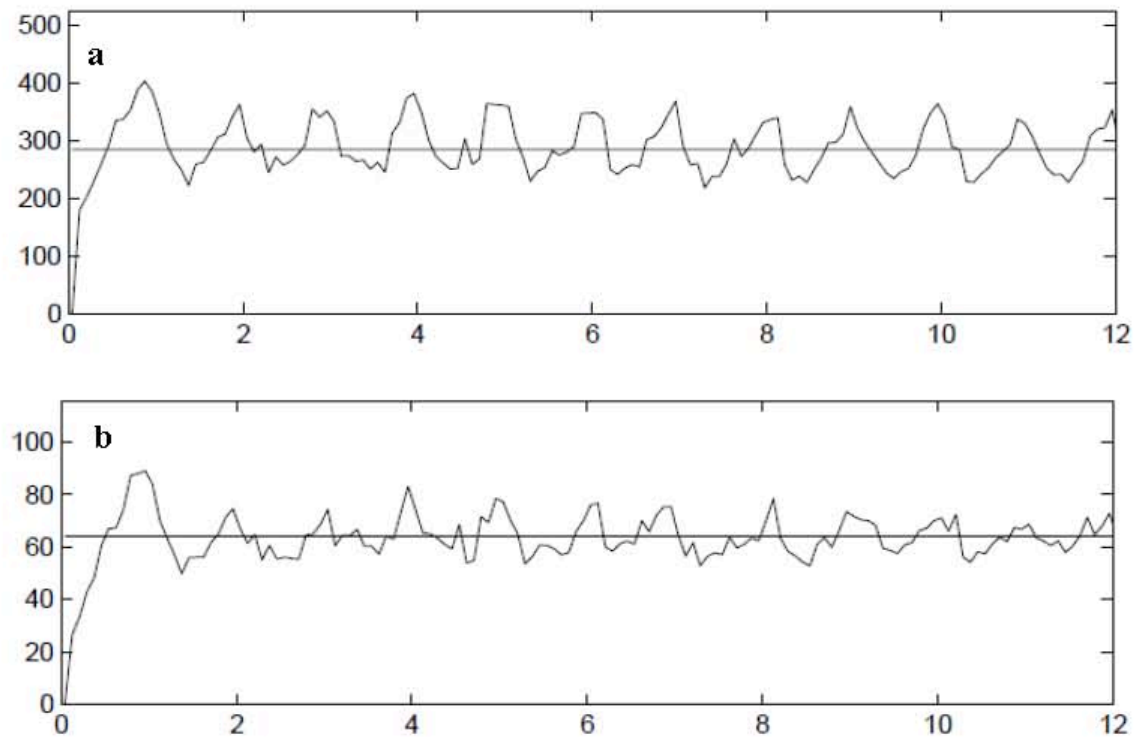

Fig. (2). Temporal evolution (model time years) of surface averaged (a) and volume averaged (b) kinetic energies [ $\left.\mathrm{cm}^{2} \mathrm{~s}^{-2}\right]$. The horizontal line represents the 13 year mean value. 


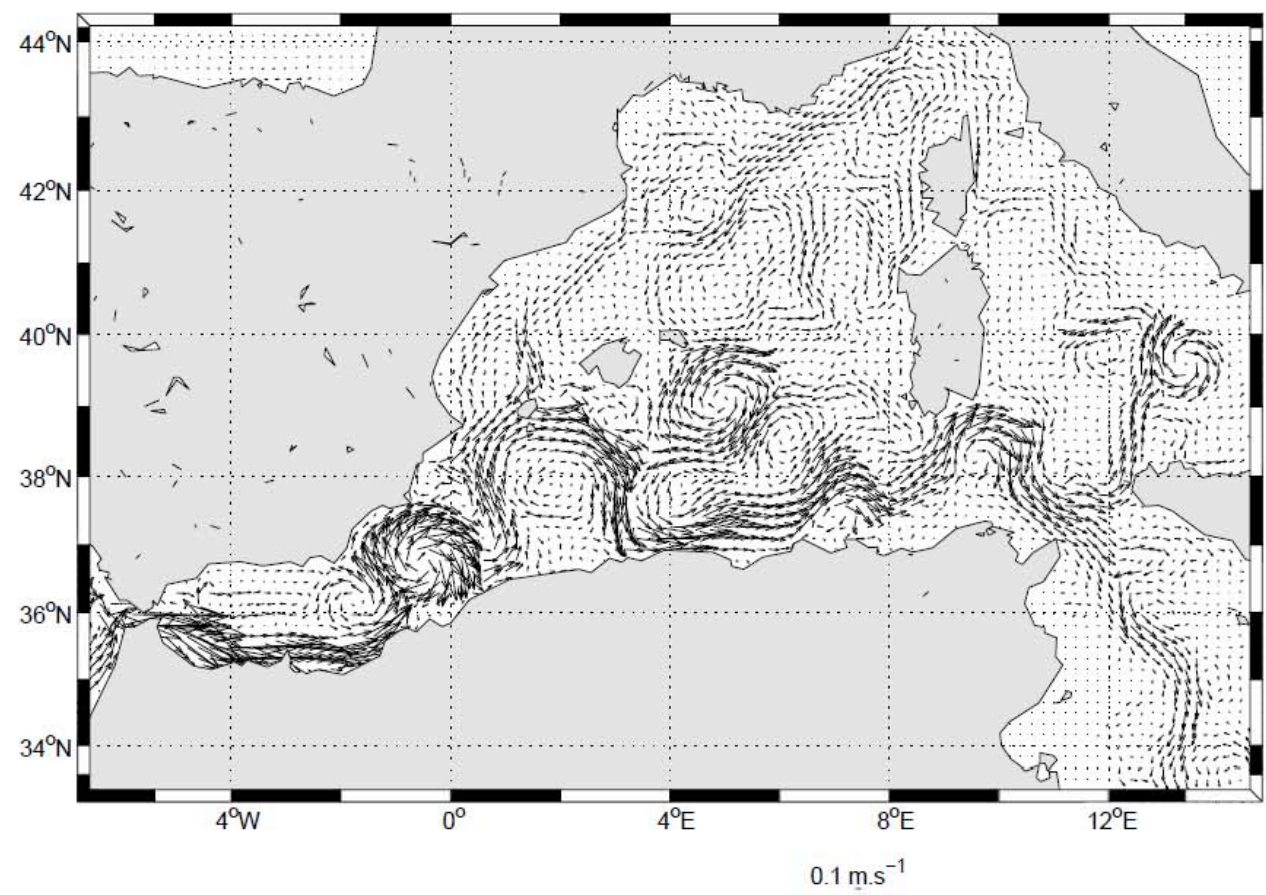

Fig. (3a). Snapshot of the surface currents simulated by the ROMS model in the western Mediterranean sea for 15 January of year 13 .

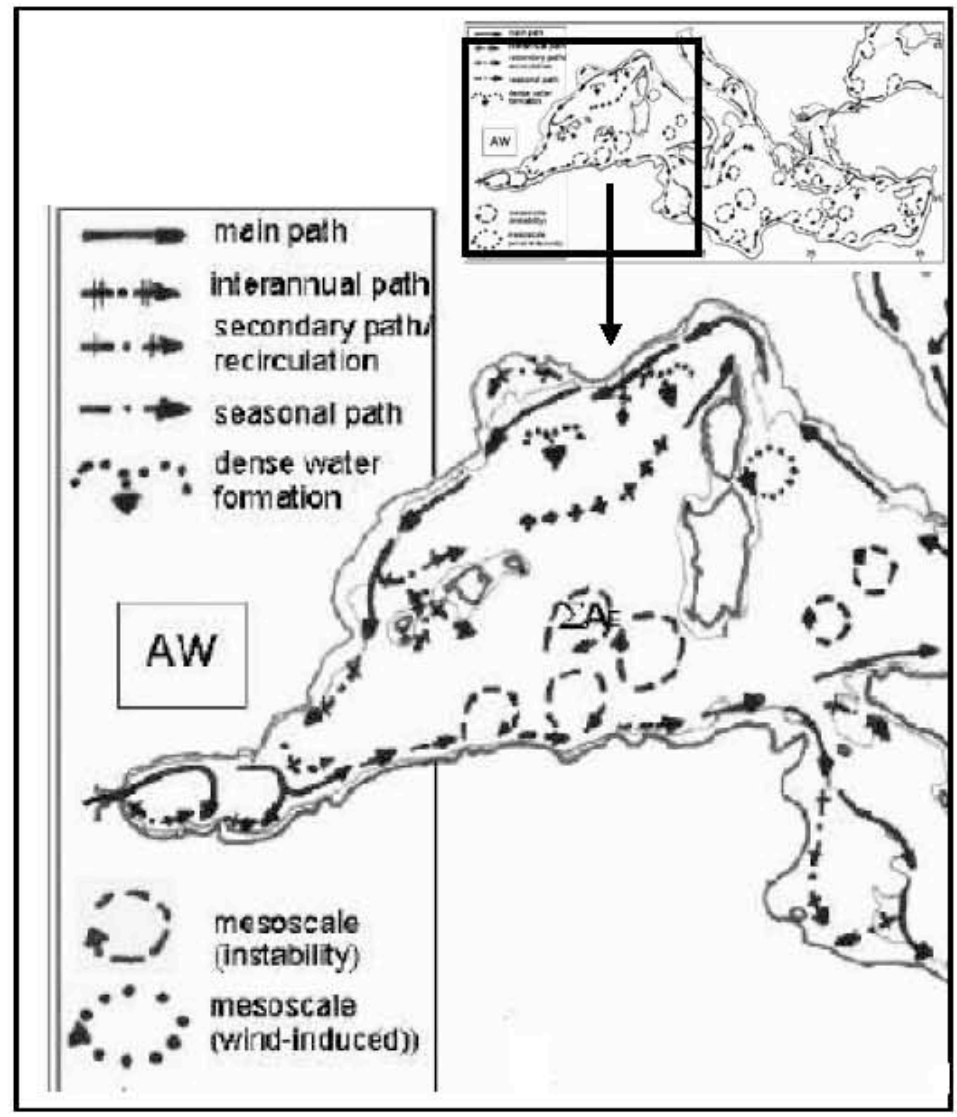

Fig. (3b). Schematic circulation of the western Mediterranean sea done by Millot et al. [19] which is consistent with available in situ and satellite data sets.

The surface currents simulated by the ROMS model (Fig. 3a) is in agreement with the schematic circulation, presented by Taupier-Letage et al. [19] (Fig. 3b), which is consistent with available in situ and satellite data sets. The ROMS model reproduced the large scale and the meso-scale eddies similar to that obtained with a numerical model of the Mediterranean sea forced with daily atmospheric forcing with a spatial resolution $0.5^{\circ}[7]$. 
The particle motion is calculated by the ROMS eulerian velocity using a fourth-order accurate Adams-BashfordMoulton predictor-corrector scheme. Transport of particles relied only on advection, as no diffusion term is introduced. Linear interpolations in time and space of the velocity field are used. To explore the transport processes on the surface and intermediate layers, passive particles are constrained to move horizontally.

\section{SINGLE PARTICLE DISPERSION}

The single-particle dispersion of an ensemble of advected particles is defined as:

$$
A^{2}\left(t, t_{0}\right)=<\left(x_{i}(t)-x_{i}\left(t_{0}\right)\right)^{2}>
$$

where $<\ldots>$ is an average over an ensemble of particles, $x_{i}(t)$ the position of the $i$-th particle at time $t$ and $t_{0}$ is the release particle time.

In isotropic homogenous and stationary flows, the asymptotic ballistic and diffusive regimes of the single particle dispersion can be obtained by the Taylor theorem [20].

$$
\begin{aligned}
& A^{2}(t) \approx 2 E t^{2} \text { when } t \rightarrow 0 \text { (ballistic) } \\
& A^{2}(t) \approx 2 \mathrm{~K} t \text { when } t \rightarrow \infty \text { (diffusive) }
\end{aligned}
$$

Where $E$ is the mean Lagrangian kinetic energy and $\mathrm{K}$ the eddy diffusivity.

Numerical experiments on the dispersion of neutrally buoyant particles in two-dimensional turbulent flows have shown the existence of a superdiffusive regime at intermediate times related to the topology of the turbulent field [9]. This link is due to the contribution of rotation and deformation to the square of the velocity gradient [21]:

$$
\|\nabla U\|^{2}=\frac{1}{2}\left(\omega^{2}+s^{2}\right)
$$

where $U$ is the eulerien velocity field. $\omega$ refers to the vorticity and $\mathrm{s}$ to the deformation:

$$
\begin{aligned}
& \omega=\frac{\partial v}{\partial x}-\frac{\partial u}{\partial y}, s^{2}=s_{1}^{2}+s_{2}^{2}, \\
& s_{1}=\frac{\partial u}{\partial x}-\frac{\partial v}{\partial y}, s_{2}=\frac{\partial v}{\partial x}+\frac{\partial u}{\partial y}
\end{aligned}
$$

To study the dynamic of the enstrophy cascade, Weiss [22] has used a partition to the turbulent field, which was adopted by many authors [9-23]. If the strain rate along a particle path is slowly varying with respect to the vorticity gradient, the lagrangian evolution of $\nabla \omega$ is given by a linear differential equation:

$$
\nabla \omega \approx \exp \left( \pm \frac{1}{2} W^{\frac{1}{2}} t\right)
$$

where $W=s^{2}-\omega^{2}$

The Okubo-Weiss parameter $\mathrm{W}$, allows to separate the flow in two distinct domains: elliptic regions are dominated by rotation and characterized by $\mathrm{W}<0$, while hyperbolic regions are dominated by deformation and characterized by $W>0$. Elliptic regions correspond to the coherent vortices which constitute particle traps for passive tracers and induce, at intermediate times, an anomalous dispersion law $A^{2} \propto t^{\frac{5}{3}}$. Hyperbolic domains correspond to the back-ground field and the circulation cells around vortices. The anomalous dispersion is characterized by a scaling law $A^{2} \propto t^{\frac{5}{4}}$.

The Okubo-Weiss parameter was used by Isern-Fontanet et al. [4] to analyze and identify the spatial structure of the elliptic regions in the Algerian basin from satellite sea Level Anomaly maps (SLA). Their results confirmed that the spatial distribution of Algerian eddies is very similar to the two-dimensional coherent eddies. Due to this similarity, we have extended our study to the particle dispersion in the western Mediterranean basin.

\section{SURFACE AND INTERMEDIATE DEPTH DISPER- SION IN THE ALGERIAN BASIN}

After a numerical simulation of 13 years, 2483 passive particles are homogenously seeded at the surface (precisely at $\mathrm{h}=44 \mathrm{~m}$ ) and at $500 \mathrm{~m}$ depth. The particles are advected during two months. All the simulated isobaric trajectories evolve at the depth of their deployment. The initial positions are located between $35^{\circ}$ and $43^{\circ} \mathrm{N}$ in latitude and $6^{\circ} \mathrm{W}$ and $12^{\circ} \mathrm{E}$ in longitude. The surface particle trajectories during 5 days are shown on Fig. (4a), where several vortices with different scale are present. In the western part of the basin, an anticyclonic gyre which occupies the whole width of the basin is centered on $1^{\circ} \mathrm{W}$ [24]. Representative particle trajectories at the surface are shown on Fig. (4b), with stars representing their initial positions. Particles 1, 2, 3 and 4 progress from west to east and move toward two branches at the Sicilian Strait as described previously [1,2]. Particles 5 and 6 move to the west showing a cyclonic path of the water surface circulation. After two months of simulations (figure not shown), calculations show that some advected particles are ejected from the coherent structures and concentrate in circulation cells. At $500 \mathrm{~m}$ depth, particle trajectories after 5 days (Fig. 5a) indicate the presence of coherent vortices colocated with the surface ones. The vertical extent of some Algerian Eddies exceeds $500 \mathrm{~m}$. At the final stage (figure not shown), the particles have a quasi-homogenous repartition in the basin except in the Sicilian Strait and the coastal domains where the depth is less than $500 \mathrm{~m}$. Selected trajectories at $500 \mathrm{~m}$ depth, displayed on Fig. (5b), show that particles move from east to west in agreement with the intermediate circulation scheme $[1,2]$.

The time spectra of surface and intermediate absolute dispersion averaged over all particles are represented on Fig. (6). The asymptotic behaviors at small and large times are observed. The Lagrangian integral time scale at the surface is about 2 days, but it exceeds 4 days at $500 \mathrm{~m}$ depth. The surface dispersion displays an intermediate dispersion regime characterized by a power law $\mathrm{A}^{2}=\mathrm{t}^{\mathrm{r}}$ with $\mathrm{r}=1.44$ between the days 2 and 40. This behavior is the superposition of the two- 


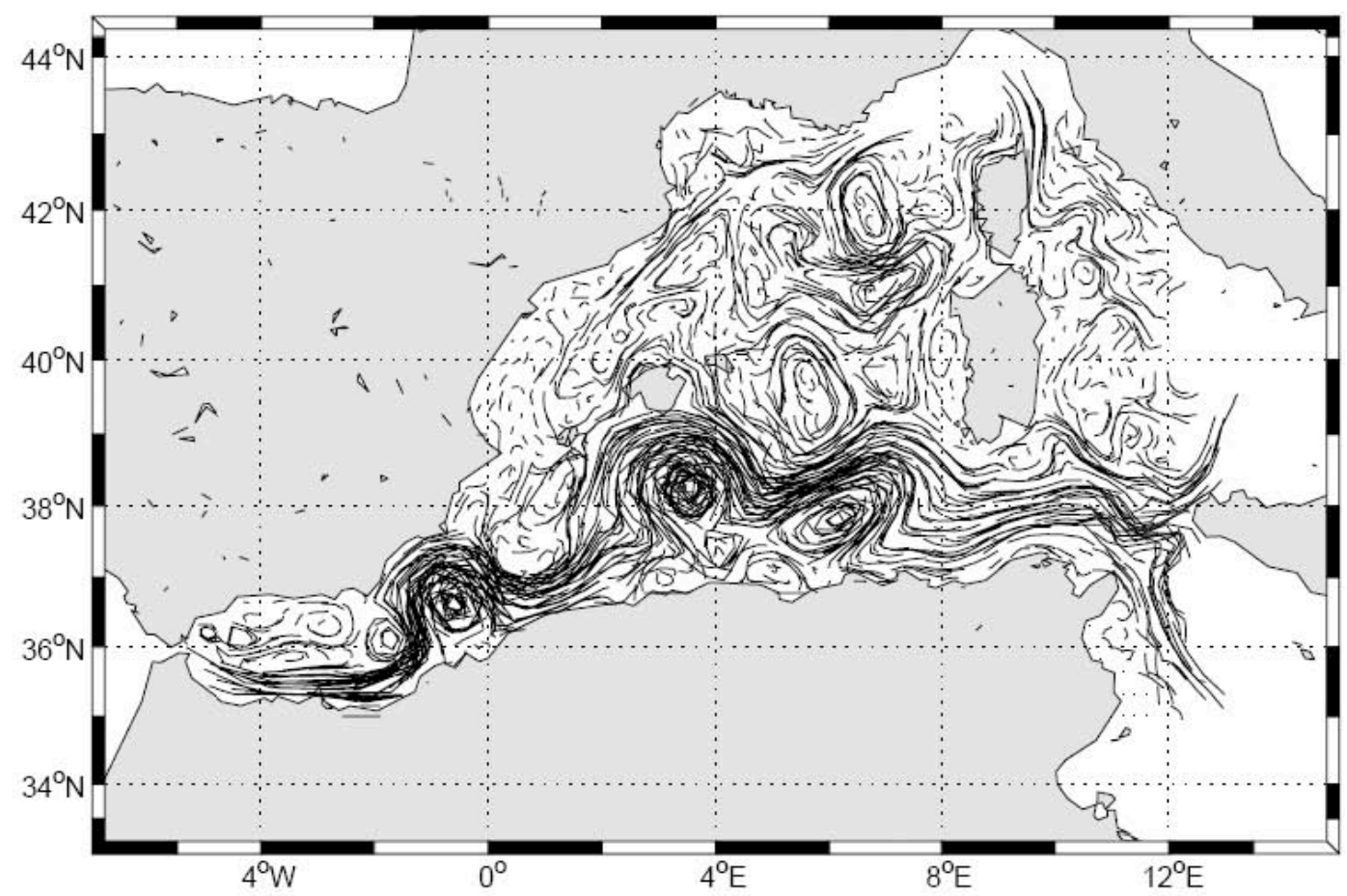

Fig. (4a). Surface particle trajectories after 5 days of simulation with the ROMS model.

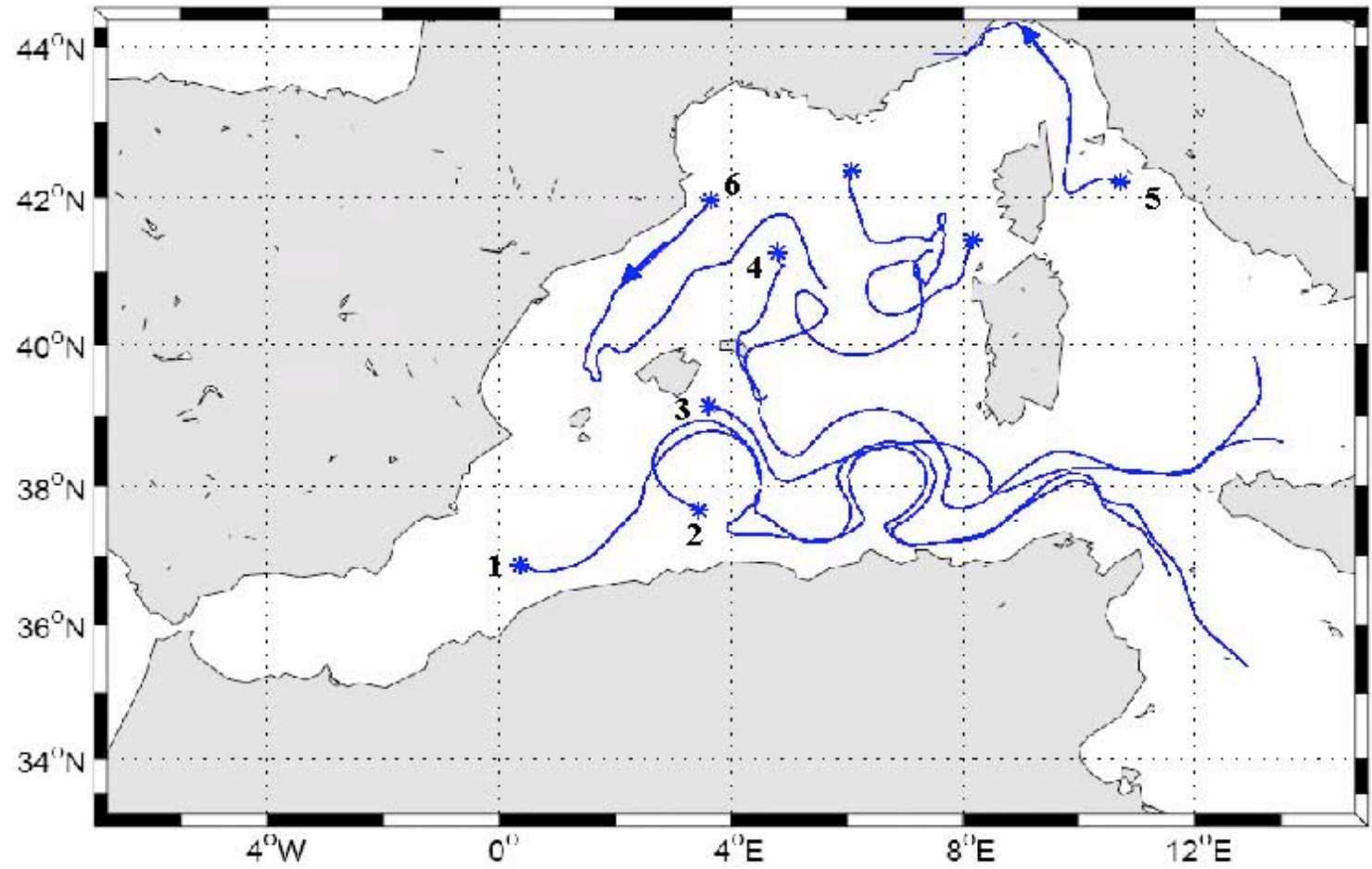

Fig. (4b). Trajectories of some surface particles. The stars represent their initial positions. Particles 1, 2, 3 and 4 progress from West to East and move toward two branches at the Sicilian Strait. Particles 5 and 6 move to the West showing a cyclonic path of the water surface circulation.

dimensional distinct regimes associated to hyperbolic and elliptic domains [9]. At $500 \mathrm{~m}$ depth, the same dispersion law $\left(\mathrm{A}^{2}=\mathrm{t}^{\mathrm{r}}\right)$ is obtained but only for 6 days between days 4 and 10). The surface time scale of the intermediate dispersion regime is longer than that at depth due to stronger coherent vortices. Veneziani et al. $[25,26]$ obtained similar spectra in their analysis of in situ and of MICOM-simulated floats launched at $700 \mathrm{~m}$ depth, in the North Atlantic region. Here, the Brownian regime is reached after 40 days at the surface, and after 20 days at $500 \mathrm{~m}$ depth. 


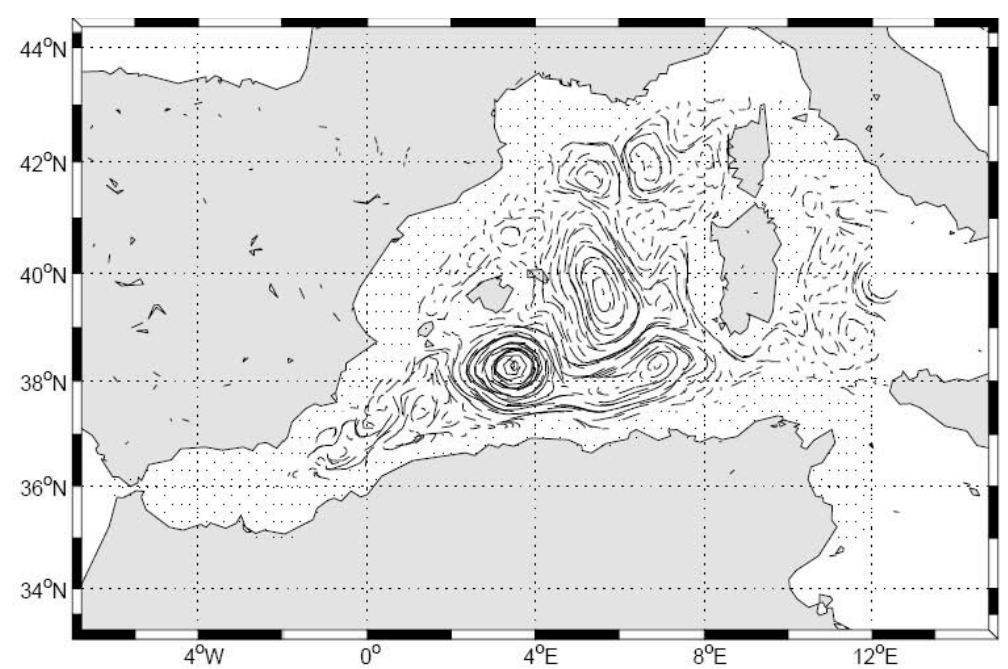

Fig. (5a). Particle trajectories after 5 days of simulation at $500 \mathrm{~m}$ depth.

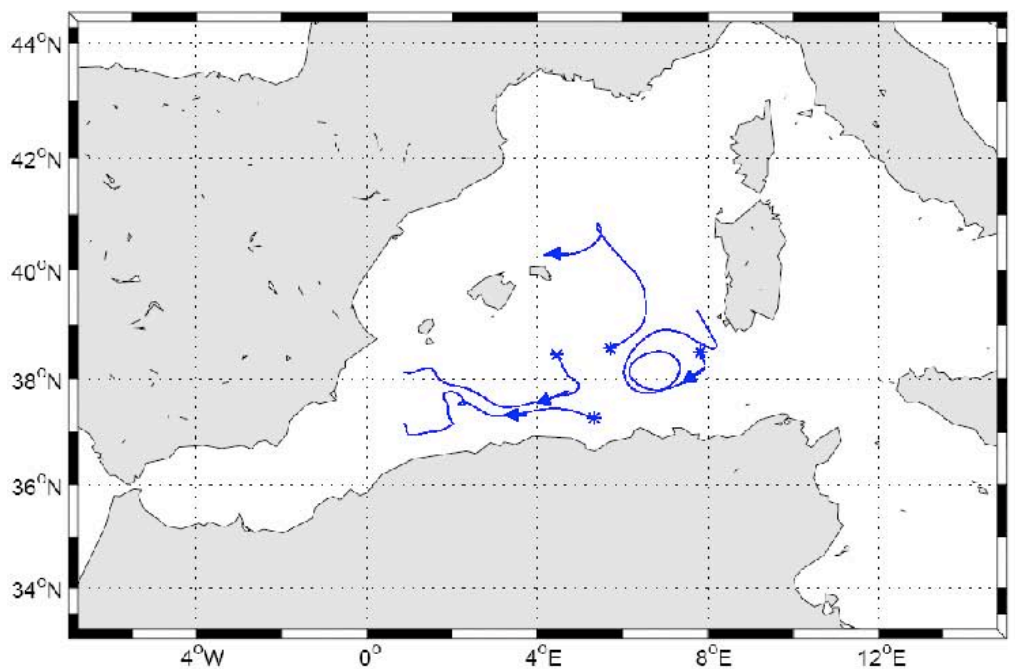

Fig. (5b). Trajectories of a few particles at $500 \mathrm{~m}$ depth. The stars represent the initial positions. These particles move from East to West.

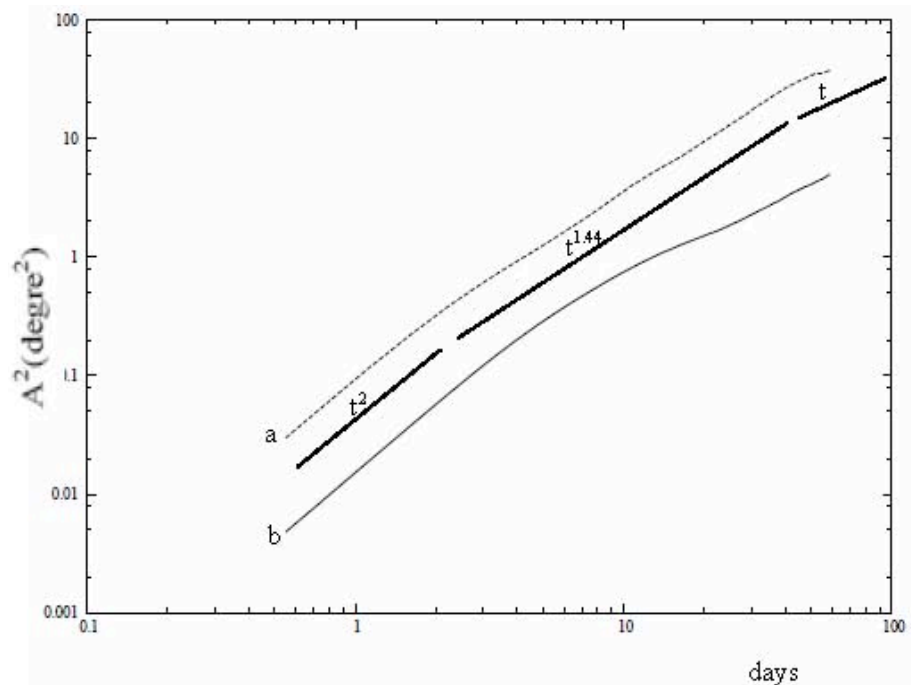

Fig. (6). Temporal evolution (model time- days) of the surface (a) $(\mathrm{h}=44 \mathrm{~m})$ and intermediate (b) absolute dispersion (h=-500m). The straight lines represent the asymptotic and anomalous behaviors.

\section{CONCLUSION}

We have presented numerical simulations with the ROMS model to study the dispersive properties of passives particles homogenously seeded at the surface and at $500 \mathrm{~m}$ depth in the western Mediterranean Sea. The particle trajectories describe the mesoscale structures of the western 
Mediterranean Sea, in agreement with observational and numerical analysis. The long lifetime and the trapping ability of Algerian eddies induce an intermediate superdiffusive regime for particle dispersion where the behavior is the superposition of two regimes of two-dimensional turbulence, associated to the hyperbolic and the elliptic domains. The superdiffusive surface regime is longer than the $500 \mathrm{~m}$ depth one, due to the weaker influence of the vortices at this depth. Due to the advance in modern computing, the floats model can complement Lagrangian data in the ocean and provide an appropriate background to target measurement campaigns.

\section{REFERENCES}

[1] Millot C. Circulation in the western mediterranean sea. Oceanol Acta $1985 ; 10: 143-9$.

[2] Millot C. Circulation in the western Mediterranean Sea. J Mar Syst 1999; 20: 423-42.

[3] Millot C, Taupier-Letage I. Additional evidence of LIW entrainment across the Algerian Basin by mesoscale eddies and not by a permanent westward flow. Prog Ocean 2005; 66: 231-50.

[4] Isern-Fontanet J, Font J, García-Ladona EE, Millot C, Taupier LI. Spatial structure of anticyclonic eddies in the Algerian basin (Mediterranean Sea) analyzed using the Okubo-Weiss parameter. Deep Sea Res II 2004; 51: 3009-28.

[5] Alhammoud B, Béranger K, Mortier L, Crépon M. Surface circulation of the Levantine Basin: comparison of model results with observations. Prog Oceanogr 2005; 66(2-4): 299-320.

[6] Testor P, Gascard JC. Large scale flow separation and mesoscale eddy formation in the Algerian Basin. Prog Oceanogr 2005; 66 (24): 211-30.

[7] Béranger K, Mortier L, Crépon M. Seasonal variability of water transport through the Straits of Gibraltar, Sicily and Corsica, derived from a high-resolution model of the Mediterranean circulation. Prog Oceanogr 2005; 66: 341-64.

[8] Provenzale A. Transport by coherent barotropic vortices. Annu Rev Fluid Mech 1993; 1: 55-93.

[9] Elhmaidi D, Provenzale A, Babiano A. Elementary topology of two dimensional turbulence from a Lagrangian viewpoint and singleparticle dispersion. J Fluid Mech 1993; 257: 533-58.

[10] Shchepetkin AF, McWilliams JC. The regional oceanic modeling system (ROMS): a split-explicit, free-surface, topography following - coordinate oceanic model. Ocean Mod 2005; 9: 347-404.
[11] Penven P, Marchesiello P, Debreu L, Lefèvre J. Software tools for pre - and post -processing of oceanic regional simulations. Environ Model Softw 2008; 23: 660-2.

[12] Penven P, Tan T. ROMSTOOLS users's Guide. IRD. Technical report 2007. http://www.brest.ird.fr/Romstools

[13] Smith WHF, Sandwell DT. Global sea floor topography from satellite altimetry and ship depth soundings. Science 1997; 227: 1956-62.

[14] Haidvogel DB, Arango HG, Hedstrom K, et al. Model evaluation experiments in the north atlantic basin: simulations in nonlinear terrain-following coordinates. Dyn Atmos Ocean 2000; 32: 239-81.

[15] Song Y, Haidvogel DB. A semi-implicit ocean circulation model using a generalized topography-following coordinate system. J Comp Phys 1994; 115 (1): 228-44.

[16] Conkright ME, Locarnini RA, Garcia HE, et al. World Ocean Atlas: Objective Analyses, Data Statistics, and Figures, CD-ROM Documentation, National Oceanographic Data Center, Silver Spring, MD 2001.

[17] Marchesiello P, McWilliams JC, Shchepetkin A. Open boundary condition for long-term integration of regional oceanic models. Ocean Model 2001; 3: 1-21.

[18] Da Silva AM, Young CC, Levitus S. Atlas of surface marine data. algorithms and procedures. Technical Report U.S. Department of commerce, NOAA 1994; Vol. 1.

[19] Millot C. Taupier-Letage I. - 2005 Circulation in the Mediterranean Sea. Handbook of Environmental Chemistry, Part K, SpringerVerlag Berlin Heidelberg 2005; Vol. 5: pp. 29-66.

[20] Taylor GI. Diffusion continuos mouvements. Proc Lond Math Soc 1921; 20: 196-212.

[21] Okubo A. Horizontal dispersion of floatable particles in the vicinity of velocity singularities such as convergences. Deep Sea Res 1970; 17: 445-54.

[22] Weiss J. The dynamics of enstrophy transfer in two-dimensional hydrodynamics. Phys D 1991; 48: 273-94.

[23] McWilliams J. The emergence of isolated coherent vortices in turbulent flow. J Fluid Mech 1984; 146: 21-43.

[24] Herbaut C, Martel F, Crépon M. A sensitivity study of the general circulation of the Western Mediterranean Sea Part II: The response to atmospheric forcing. J Phys Oceanogr 1997; 27: 2126-45.

[25] Veneziani M, Griffa A, Reynolds AM, Mariano AJ. Oceanic turbulence and stochastic models from subsurface Lagrangian data for the Northwest Atlantic Ocean. J Phys Oceanogr 2004; 34: 1884-906.

[26] Veneziani M, Griffa A, Garraffo ZD, Chassignet EP. Lagrangian spin parameter and coherent structures from trajectories released in a high-resolution ocean model. J Mar Res 2005; 63: 753-88. 